\title{
Localization of alpha-uterine protein in human endometrium
}

\author{
C. H. W. Horne, W. F. Paterson* and R. G. Sutcliffe* \\ Department of Pathology, University Medical Buildings, Foresterhill, Aberdeen AB9 2ZD, and \\ *Institute of Genetics, Glasgow University, Church Street, Glasgow G11 5JS, U.K.
}

\begin{abstract}
Summary. Immunoperoxidase staining was used to investigate the origin of human alpha-uterine protein (AUP). Specific staining was observed in the glandular epithelium of the endometrium during the secretory phase of the menstrual cycle and during pregnancy, and in a patient on an oestrogen-progestagen contraceptive pill. The pattern of staining strongly suggests that AUP is secreted into the uterine lumen. The location and concentration of AUP in the uterus may explain the relative concentrations of AUP in amniotic fluid and maternal serum.
\end{abstract}

\section{Introduction}

Alpha-uterine protein (AUP) is a human protein which was originally detected in the amniotic fluid during the second trimester. The protein has also been detected in endometrial tissue from pregnant and non-pregnant women, and at very low concentration in the blood of pregnant women (Sutcliffe, Brock, Nicholson \& Dunn, 1978; Sutcliffe, Bolton, Sharp, Nicholson \& MacKinnon, 1980). This protein has also been independently identified by Joshi, Ebert \& Swartz (1980a) and Joshi, Ebert \& Smith (1980b), who called it progestagen-dependent endometrial protein (PEP) since, in non-pregnant subjects, its synthesis was detected in secretory but not in proliferative endometrium. AUP and PEP have a similar structure and give serological reactions of identity (Sutcliffe, Joshi \& Paterson, 1982). We have used an indirect immunoperoxidase antibody staining technique to determine the cellular localization of AUP in the endometrium of pregnant and non-pregnant women, and in the amnion and chorion.

\section{Materials and Methods}

Paraffin-wax embedded blocks of placentae and endometria which had been fixed for 1-6 months in neutral buffered formalin (4\% formaldehyde $+4 \% \mathrm{NaH}_{2} \mathrm{PO}_{4}+6.5 \% \mathrm{Na}_{2} \mathrm{HPO}_{4}$ ) were obtained from the files of the Pathology Department in Aberdeen and also from material fixed shortly before the present experiments. Samples of endometrium and placenta were obtained with ethical permission from women undergoing termination of pregnancy (8-13 weeks) or Caesarian section (34-40 weeks).

Rabbit anti-AUP antiserum was prepared in rabbits using purified AUP (Sutcliffe et al., 1980). AUP is a highly stable protein, remaining immunologically detectable after treatment with $3 \mathrm{M}$ caotropic ions, $5 \mathrm{M}$-guanidine $\mathrm{HCl}, 8 \mathrm{M}$-urea or $\mathrm{pH} 2.8$ (Sutcliffe, Kukulska, Nicholson \& Paterson, 1979; Kukulska-Langlands, 1980). 


\section{Immunoperoxidase technique}

The method was as described by Sternberger, Hardy, Coculis \& Meyer (1970). Slides were dewaxed with two changes of xylol for $10 \mathrm{~min}$ each. All reactions were carried out at room temperature. Endogenous peroxidase activity was blocked treating the sections with $0.5 \% \mathrm{H}_{2} \mathrm{O}_{2}$ in methanol for 30 min (Streefkerk, 1972). Subsequent to this, sections were exposed to $0.1 \%$ trypsin in $0.1 \% \mathrm{CaCl}_{2}\left(\mathrm{pH} \mathrm{7.8)}\right.$ for $20 \mathrm{~min}$ at $37^{\circ} \mathrm{C}$. All dilutions of antisera and porcine sera were made in $0.154 \mathrm{M}-\mathrm{NaCl}-5 \mathrm{~mm}$-Tris- $\mathrm{HCl}, \mathrm{pH} \mathrm{7.8}$. Each was applied to the section for 30 min, followed by 3 washes of 10 min each with $0.154 \mathrm{M}-\mathrm{NaCl}-5 \mathrm{mM}$-Tris- $\mathrm{HCl}, \mathrm{pH} \mathrm{7.8.}$ Non-specific background staining was reduced by exposing sections to a $1 / 5$ dilution of normal pig serum. The specific antiserum was used at a dilution of $1 / 200$ throughout. The pig anti-rabbit immunoglobulin (Dakopatts, Copenhagen, Denmark) was then applied at a 1/40 dilution and the peroxidase-antiperoxidase complex (Dakopatts) at a dilution of $1 / 100$. Peroxidase activity was shown by staining with diaminobenzidine $(30 \mathrm{mg}$ in $100 \mathrm{ml} 50 \mathrm{~mm}$-Tris- $\mathrm{HCl}, \mathrm{pH} \mathrm{7.8})$ for 10 min. Slides were counterstained with haematoxylin.

Purified AUP ( $5 \mu \mathrm{g}$ in $30 \mu \mathrm{l} 0.154 \mathrm{M}-\mathrm{NaCl}-5 \mathrm{~mm}$-Tris-HCl, $\mathrm{pH} 7.8$ ) was used to adsorb the specific AUP antiserum $(5 \mu \mathrm{l})$. The adsorption proceeded for $30 \mathrm{~min}$ at $37^{\circ} \mathrm{C}$ and the mixture was then diluted to a final concentration of antiserum of $1 / 200$ and the test sections were compared with the appropriate adsorption control.

\section{Quantitation of AUP}

AUP was assayed in tissue homogenates by antibody-antigen crossed electrophoresis (Sutcliffe et al., 1978). Protein was determined by the method of Lowry, Rosebrough, Farr \& Randall (1951).

\section{Results}

On all occasions, the antibody staining reported in this paper could be absorbed by the addition of purified AUP to the antiserum before the experiment (see Pl. 1, Figs 5 and 6). Since the initial sample of AUP was homogeneous (Sutcliffe et al., 1980) this is evidence for the specificity of the observed staining. Additionally, in all the experiments, no staining was observed when the anti-AUP antiserum was replaced with non-immune rabbit serum.

No staining was observed in tissue secretions of proliferative endometrium. During the early secretory phase, weak staining was observed in the glandular epithelial cells and their secretions.

\section{PLATE 1}

Fig. 1. Section of human endometrium in the secretory phase of the menstrual cycle, showing localization of AUP in glandular epithelial cells (E). The section is counterstained with haematoxylin and eosin (H \& E). The surrounding stroma (S) does not show the golden brown colour typical of peroxidase staining. $\times 235$.

Fig. 2. Section of endometrium from a patient on an oestrogen-progestagen contraceptive pill, showing staining for AUP in the microtubular glandular epithelial cells (ME). There is no peroxidase staining in the surrounding stroma (S). Counterstained with H \& E. $\times 235$.

Figs 3 and 4. Sections of endometrium from a patient in the 8 th week of pregnancy. There is localization of AUP in the glandular epithelial cells (E), and very heavy staining of the luminal secretions (Fig. 3). Some heavy staining is evident on the luminal border of some epithelial cells (see arrows) (Fig. 4). The surrounding stroma did not stain. See Figs 5 and 6 for adsorption controls. Fig. 3, $\times$ 94; Fig. 4, $\times 235$.

Figs 5 and 6. Adsorption controls for Figs 3 and 4, stained after the rabbit anti-AUP had been adsorbed with purified AUP. $\mathrm{L}=$ lumen of gland. Fig. 5, $\times 94$; Fig. $6, \times 235$. 
PLATE 1
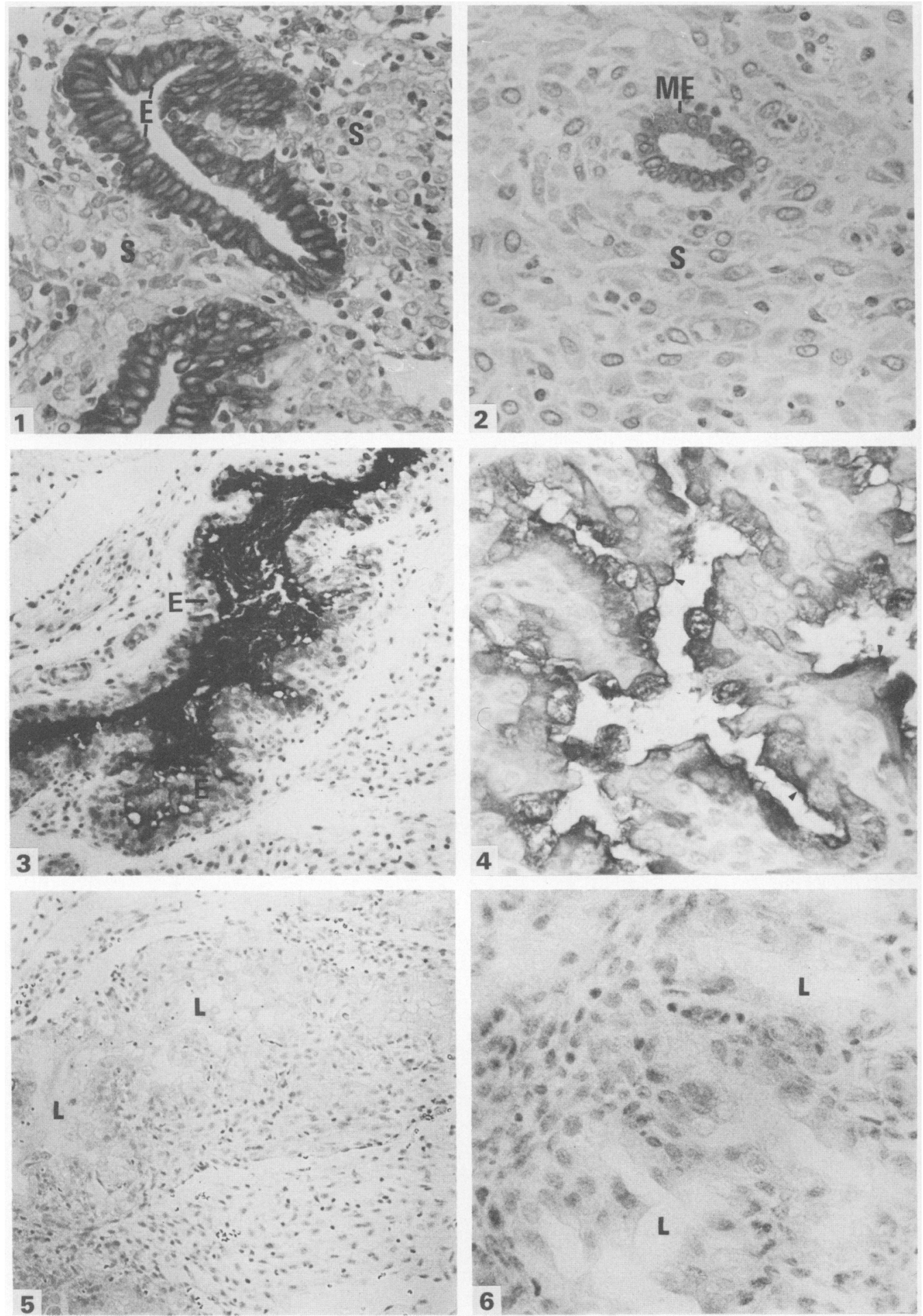
Marked staining was observed in the advanced secretory phase, especially in the glandular epithelial cells (Pl. 1, Fig. 1). In a patient taking an oestrogen-progestagen-based contraceptive pill, the typical microtubular histology was observed and the epithelial gland cells stained positively for AUP (PI. 1, Fig. 2). There was no convincing staining for AUP in stromal cells.

During pregnancy, there was strong staining of the endometrial glandular epithelium and its secretions (Pl. 1, Fig. 3). In some glands there was evidence for a concentration of AUP on the luminal aspect of the glandular epithelium.

The concentration of AUP was assayed in extracts of endometrium from pregnancies from 8 to 13 weeks and 34 to 40 weeks (Text-fig. 1). Much higher levels were observed earlier in pregnancy.

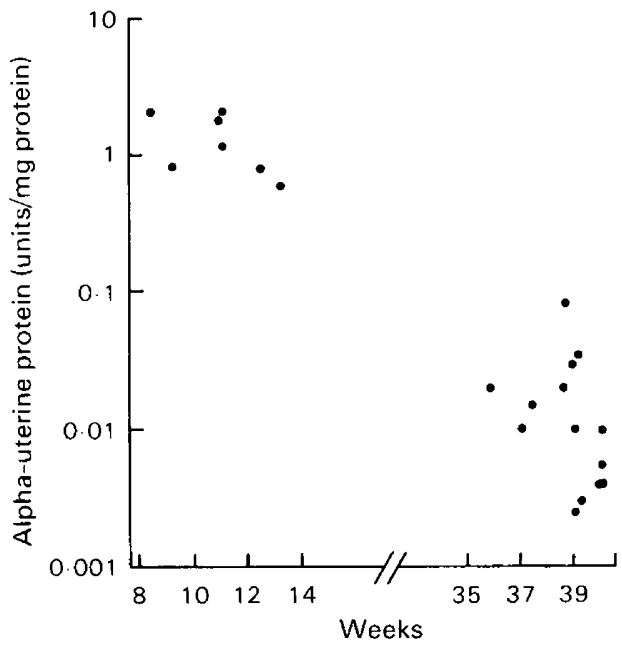

Text-fig. 1. The concentration of AUP (determined by AACE) in samples of decidua taken at various stages of pregnancy.

Although traces of AUP were detectable in dissected samples of amnion or reflected chorion by AACE, no AUP was detectable within the cells of those tissues, nor was it detectable in trophoblastic cells.

\section{Discussion}

This paper shows for the first time that AUP is present in the epithelial cells and secretions of the endometrial glands during the secretory phase of the menstrual cycle and also during pregnancy. It is presumably these cells that are responsible for the synthesis of AUP observed by Joshi et al. (1980a) in secretory and pregnant endometrial glandular epithelium. The absence of AUP from proliferative glandular epithelial cells is in accordance with the failure of Joshi et al. (1980a) to detect synthesis of AUP at that stage, although a very low level of synthesis cannot be excluded by either experiment. It was this relative lack of AUP synthesis in proliferative endometrium that led Joshi et al. (1980a) to conclude that AUP synthesis is progestagen-dependent. That conclusion is supported by the present finding of AUP in the glandular epithelium of a patient taking a combined oestrogen-progestagen contraceptive pill (PI. 1, Fig. 2) and whose endometrial glands were in the typical narrow and straight microtubular form (Azzopardi \& Zayid, 1967; Haines \& Taylor, 1975). While oestrogen at low levels may be necessary to permit this synthesis of AUP, if only by inducing progesterone receptors (Bayard, Damilano, Robel \& 
Baulieu, 1978; Janne, Kontula, Luukkainen \& Vihko, 1975), there seems to be an absolute requirement for progesterone if marked synthesis is to occur.

The results show that AUP was concentrated at the luminal border of some glandular epithelial cells and that it was present in the lumen of the glands. This strongly suggests that the protein is a secretory product of the uterus, both during the progestational phase of the menstrual cycle and during pregnancy. The protein seems to be exported from the uterus into the uterine lumen, rather than into the maternal circulation and this may account for the relatively high concentration of AUP in second trimester amniotic fluid (Sutcliffe et al., 1978) in comparison with the concentration of AUP in maternal serum, which is approximately 1/500th of the level in amniotic fluid (unpublished). The concentration of AUP in the pregnant uterus is maximal in early pregnancy (Text-fig. 1) and this probably explains the high concentration of AUP in amniotic fluid at that time. We do not know if AUP is expressed in uterine epithelial cells adjacent to the uterine lumen.

Although it is the first characterized human progesterone-induced uterine protein, the function of AUP remains unknown. Preliminary observations show that it has no significant affinity for progesterone (Paterson, 1981). It is not known whether the protein functions before or during pregnancy, or at both times. The protein may be synthesized during pregnancy in parallel with other more essential proteins which have a common form of induction. There are three general areas in which the protein might well have a function. (1) During the normal menstrual cycle, perhaps as a factor during menstruation to prevent excessive blood clotting, or to provide extra anti-microbial protection; (2) as a factor aiding gamete mobility or survival, or in sperm capacitation, although it is probably secreted too late in the menstrual cycle for this to be very likely, and (3) during early pregnancy, as an aid to implantation, or as a carrier of ions, co-factors or hormones from the uterus to the developing conceptus.

This work was supported by an M.R.C. project grant to R.G.S.

\section{References}

Azzopardi, J.G. \& Zayid, I. (1967) Synthetic progestagen-oestrogen therapy and uterine changes. J. clin. Path. 20, 731-738.

Bayard, F., Damilano, S., Robel, P. \& Baulieu, E.-E. (1978) Cytoplasmic and nuclear estradiol and progesterone receptors in human endometrium, $J$. clin. Endocr. Metab. 46, 635-648.

Haines, M. \& Taylor, C.W. (1975) Gynaecological Pathology. Churchill Livingstone, Edinburgh.

Kukulska-Langlands, B.M. (1980) Studies on human placental proteins. Ph.D. thesis, Glasgow University.

Lowry, O.H., Rosebrough, N.J., Farr, A.L. \& Randall, R.J. (1951) Protein measurement with the Folin phenol reagent. J. biol. Chem. 193, 265-275.

Janne, O., Kontula, K., Luukkainen, T. \& Vihko, R. (1975) Oestrogen-induced progesterone receptor in human uterus. J. Steroid Biochem. 6, 501-509.

Joshi, S.G., Ebert, K.M. \& Swartz, D.P. (1980a) Detection and synthesis of a progestagen-dependent protein in human endometrium. J. Reprod. Fert. 59 , 273-285.

Joshi, S.G., Ebert, K.M. \& Smith, R.A. (1980b) Properties of the progestagen-dependent protein of the human endometrium. J. Reprod. Fert. 59. 287-296.

Paterson, W.F. (1981) Studies on human alpha uterine protein. M.Sc. thesis, University of Glasgow.
Sternberger, L.A., Hardy, P.H., Coculis, J.J. \& Meyer, H.G. (1970) The unlabelled enzyme method of immuno-histochemistry: preparation of antigenantibody complex (peroxidase-antiperoxidase) in identification of spirochetes. J. Histochem. Cytochem. 18, 315-322.

Streefkerk, J.G. (1972) Inhibition of erythrocyte pseudoperoxidase activity by treatment with hydrogenperoxide following methanol. J. Histochem. Cytochem. 20, 829-831.

Sutcliffe, R.G., Brock, D.J.H., Nichoison, L.V.B. \& Dunn, E. (1978) Fetal- and uterine-specific antigens in human amniotic fluid. J. Reprod. Fert. 54, 85-90.

Sutcliffe, R.G., Kukulska, B.M., Nicholson, L.V.B. \& Paterson, W.F. (1979) The use of antibody affinity chromotography and other methods in the study of pregnancy-associated proteins. In Placental Proteins, pp. 55-70. Eds A. Klopper \& T. Chard. Springer-Verlag, Berlin.

Sutcliffe, R.G., Bolton, A.E., Sharp, F., Nicholson, L.V.B. \& Mackinnon, R. (1980) Purification of human alpha uterine protein. J. Reprod. Fert. 58, $435-442$.

Sutcliffe, R.G., Joshi, S.G. \& Paterson, W.F. (1982) Serological identity between human alpha protein and human progestagen-dependent endometrial protein. J. Reprod. Fert. 65, 207-209. 